\title{
Dimensional and componential structure of a hierarchical organization of pain-related anxiety constructs
}

Citation for published version (APA):

Vancleef, L. M. G., Vlaeyen, J. W. S., \& Peters, M. L. (2009). Dimensional and componential structure of a hierarchical organization of pain-related anxiety constructs. Psychological Assessment, 21(3), 340-351. https://doi.org/10.1037/a0016246

Document status and date:

Published: 01/01/2009

DOI:

10.1037/a0016246

Document Version:

Publisher's PDF, also known as Version of record

Document license:

Taverne

Please check the document version of this publication:

- A submitted manuscript is the version of the article upon submission and before peer-review. There can be important differences between the submitted version and the official published version of record.

People interested in the research are advised to contact the author for the final version of the publication, or visit the DOI to the publisher's website.

- The final author version and the galley proof are versions of the publication after peer review.

- The final published version features the final layout of the paper including the volume, issue and page numbers.

Link to publication

\footnotetext{
General rights rights.

- You may freely distribute the URL identifying the publication in the public portal. please follow below link for the End User Agreement:

www.umlib.nl/taverne-license

Take down policy

If you believe that this document breaches copyright please contact us at:

repository@maastrichtuniversity.nl

providing details and we will investigate your claim.
}

Copyright and moral rights for the publications made accessible in the public portal are retained by the authors and/or other copyright owners and it is a condition of accessing publications that users recognise and abide by the legal requirements associated with these

- Users may download and print one copy of any publication from the public portal for the purpose of private study or research.

- You may not further distribute the material or use it for any profit-making activity or commercial gain

If the publication is distributed under the terms of Article $25 \mathrm{fa}$ of the Dutch Copyright Act, indicated by the "Taverne" license above, 


\title{
Dimensional and Componential Structure of a Hierarchical Organization of Pain-Related Anxiety Constructs
}

\author{
Linda M. G. Vancleef \\ Maastricht University
}

\author{
Johan W. S. Vlaeyen \\ Maastricht University and University of Leuven
}

\author{
Madelon L. Peters \\ Maastricht University
}

\begin{abstract}
Research has identified several anxiety and fear constructs that contribute directly or indirectly to the chronic course of pain. One way to gain insight into the frequently observed interrelations between these constructs may be by conceptualizing them within a hierarchical structure. In this structure, general and specific constructs are proposed at different levels of a hierarchical tree. The present study sought to find evidence for this idea by exploring the dimensional and componential structure of a hierarchical representation of pain-related anxiety constructs. Small cards describing the individual items of 9 pain-related anxiety measures were presented to undergraduate students $(N=294)$, who were asked to sort them into piles of what they perceived as items of similar meaning. Cluster analysis (additive tree analyses) revealed cluster groups that could be interpreted along the lines of the proposed hierarchical structure. Multidimensional scaling analysis showed that the similarity data are characterized by a dimension that runs from general affective to pain-specific concerns. This study thus offers empirical support for the postulation of a general and specific hierarchical ordering of these constructs. Furthermore, its results endorse the independent use of various pain-related anxiety measures in research and practice aiming to assess negative emotional constructs that contribute to pain.
\end{abstract}

Keywords: anxiety, pain, hierarchical conceptualization, dimensionality, cluster analysis

Supplemental materials: http://dx.doi.org/10.1037/a0016246.supp

Several general and more specific negative emotional constructs have been proposed as contributing directly or indirectly to the chronic course of pain (e.g., Keogh \& Asmundson, 2004; Vancleef $\&$ Peters, 2006). Negative affectivity and trait anxiety were found to be associated with higher pain intensity and pain-related disability (Keogh \& Asmundson, 2004). Both constructs are conceived as general and stable personality traits, reflecting overall negative worldviews and anxious responses to a broad range of situations.

Linda M. G. Vancleef and Madelon L. Peters, Department of Clinical Psychological Science, Maastricht University, Maastricht, The Netherlands; Johan W. S. Vlaeyen, Department of Clinical Psychological Science, Maastricht University, and Research Centre for Health Psychology, Department of Psychology, University of Leuven, Leuven, Belgium.

Johan W. S. Vlaeyen is now at the Department of Clinical Psychological Science, Maastricht University, and the Pain and Disability Research Program, University of Leuven, Leuven, Belgium.

This research was partially supported by Netherlands Organisation for Scientific Research Grant 015-001-050 (to Madelon L. Peters) and Grant 453-04-003 (to Johan W. S. Vlaeyen). The authors wish to thank Rosanne Janssen and Charlie Bonnemayer for technical support; Miriam Egberink and Adrienne Storm-Van Leeuwen for help with data collection; and Erik Schouten, Jan Schepers, and Gert Storms for statistical advice.

Correspondence concerning this article should be addressed to Linda M. G. Vancleef, Department of Clinical Psychological Science, Maastricht University, P.O. Box 616, 6200 MD Maastricht, The Netherlands. E-mail: 1.vancleef@dmkep.unimaas.nl
Furthermore, anxiety sensitivity (AS) - defined as the fear of anxiety-related symptoms that arises from the belief that these symptoms predict serious somatic, psychological, or social harm (Reiss, Peterson, Gursky, \& McNally, 1986) — has frequently been found to be related to dysfunctional responses to pain (for an overview, see Stewart \& Asmundson, 2006). In recent years, injury/illness sensitivity (IS)_-defined as an exaggerated fear of future injury or illness (Reiss, 1991; Taylor, 1993)— has been suggested as important in explaining and understanding chronic pain (Carleton, Asmundson, \& Taylor, 2005; Keogh \& Asmundson, 2004; Taylor, 1993; Vancleef \& Peters, 2006). Both AS and IS are conceived as traitlike personality constructs that are specifically related to affective responses to situations that are congruent with the fear of injury, illness, and bodily sensations.

Pain catastrophizing and fear of pain have also been recognized as playing a crucial role in the transition from acute to chronic pain. Both latter constructs are conceived to be most proximally related to the actual confrontation with pain and to have a direct influence on a patient's responses to painful experiences (Keogh \& Asmundson, 2004). There is a large body of evidence confirming the major impact of pain catastrophizing and fear of pain on the amplification of pain and associated disability (e.g., Crombez, Eccleston, Baeyens, Van Houdenhove, \& Van Den Broeck, 1999; Peters, Vlaeyen, \& Kunnen, 2002; Sullivan, Stanish, Waite, Sullivan, \& Tripp, 1998; Vlaeyen \& Linton, 2000).

Studies on the contribution of the various pain-related anxiety constructs to pain have pointed out their close interrelationship and 
partial overlap (Hadjistavropoulos, Asmundson, \& Kowalyk, 2004; Keogh \& Asmundson, 2004; McCracken, Gross, Aikens, \& Carnrike, 1996). At the same time, it has been demonstrated that, although correlations do exist, different anxiety constructs possess unique and divergent predictive values for different responses to pain (e.g., Hadjistavropoulos et al., 2004).

The growing body of research on the mutual and individual importance of these constructs stresses the need to gain an integrative view of their interrelations. One way to help achieve this is by regarding them as components of a hierarchical structure of pain-relevant negative emotional constructs (Keogh \& Asmundson, 2004). Such a structure is derived from the hierarchical model of negative emotional constructs that Lilienfeld, Turner, and Jacob (1993) proposed as a solution for the ongoing debate on the conceptual difference between trait anxiety and AS in their contribution to anxiety (see Figure 1A; see Lilienfeld, Turner, \& Jacob, 1998, for details on this controversy). In a hierarchical structure, content-specific, or lower order, constructs are hierarchically nested within more content-general, or higher order, constructs (Lilienfeld et al., 1998; Watson \& Clark, 1992).

One of the merits of hierarchical conceptualization is that while it assumes that the componential constructs are interrelated, it also considers that each component shows unique predictive variance for specific affective responses (Lilienfeld et al., 1993). In Lilienfeld's (1993) model, negative affectivity is at the top of the hierarchy, followed by three lower order factors that reflect the affect types subsumed in negative affectivity: aggression, alienation, and trait anxiety (Watson \& Clark, 1992). Trait anxiety is

A

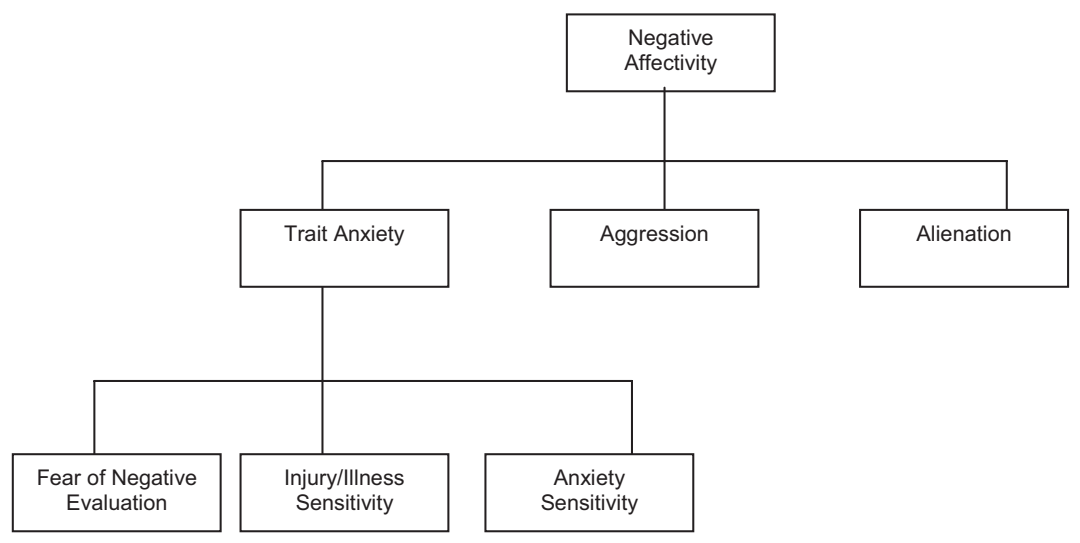

B

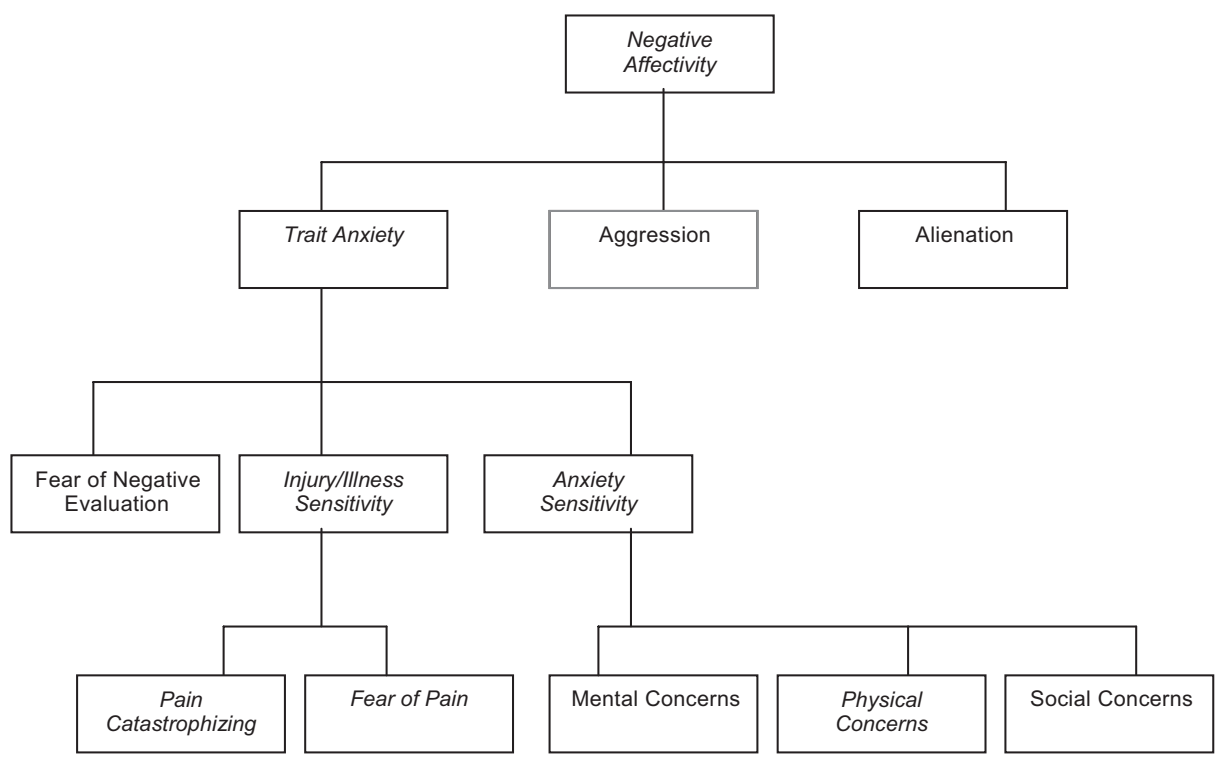

Figure 1. A: A hierarchical model of negative emotional constructs as proposed by Lilienfeld et al. (1993). B: A representation of the proposed hierarchical structure of pain-relevant negative emotional constructs as explored in the current study (terms in italics). This model is derived from Lilienfeld and colleagues' hierarchical model and extended at the lowest level with pain-specific constructs. 
then further subdivided into three lower order factors, or fundamental fears: AS, IS, and fear of negative evaluation (Lilienfeld et al., 1993; Reiss, Peterson, \& Gursky, 1988; Taylor, 1993). Support for the organization of subparts in line with this hierarchical model-such as the higher and lower order relation between negative affectivity, trait anxiety, and AS - has been reported by various authors (e.g., Lilienfeld, 1996; Norton \& Mehta, 2007; Sexton, Norton, Walker, \& Norton, 2003; Watson \& Clark, 1992).

Starting from Lilienfeld et al.'s (1993) model, a hierarchical structure for pain-relevant negative emotional constructs has been suggested (Keogh \& Asmundson, 2004; Vancleef, Peters, Roelofs, \& Asmundson, 2006; see Figure 1B). This structure focuses on the anxiety pathways in Lilienfeld's model and resembles the original up to the level of the fundamental fears. However, given the specific reference to bodily symptoms and sensations, both AS and IS are thought to be particularly relevant in considering the domain of pain (Keogh \& Asmundson, 2004; Vancleef et al., 2006). At the lowest level of the structure, two pain-specific constructs are added to the original model as lower order factors of IS: fear of pain and pain catastrophizing. In addition to this, physical, cognitive, and social concerns are incorporated as lower order factors of AS. It should be noted that the proposed hierarchical structure is supposed to be conceived as a theoretical conceptualization that still needs formal statistical testing. The structure is not definitive but open to the restructuring of its components or the addition of other, yet to be identified, constructs. Nevertheless, it offers a conceptual framework that helps one understand and structure the painrelevant negative emotional constructs both in relation to each other and with regard to their contribution to the chronic course of pain.

A diversity of self-report instruments is available for the assessment of pain-relevant emotional constructs. Researchers often choose to work with one particular measure to represent one particular construct. It is important to point out, however, that even careful psychometric evaluation does not warrant a one-to-one relation between the measure and the latent construct it represents (e.g., Kline, 2000). Furthermore, a closer look at the item content of different pain-relevant measures reveals overlap between particular items due to similarities in their broader meaning. This overlap can even be quite considerable. For example, the items "I worry that I might get a serious physical illness in the future" (injury/illness sensitivity index [ISI]; Taylor, 1993), "When my stomach is upset I worry that I might be seriously ill" (anxiety sensitivity index [ASI]; Peterson \& Heilbronner, 1987), "I worry all the time whether the pain will end" (Pain Catastrophizing Scale [PCS]; Sullivan, Bishop, \& Pivik, 1995), and "I worry when I am in pain" (Pain Anxiety Symptoms Scale [PASS-20]; McCracken \& Dhingra, 2002) are all broadly related to concerns about injury and illness, even though they have been classified according to different scales. The question therefore arises if respondents understand and respond to the items as originally intended by the authors of the questionnaire. The subtle differences in item content that underlie scale differentiation may well be lost on respondents. Also, the moderate to high degree of correlation between questionnaires seems to justify asking if these measures do in fact assess demarcated and unique latent constructs. In other words, has research on the subject rightly been segmented through the use of various separate questionnaires or has this merely resulted in a dispersion of measures reflecting the same latent construct?
In the present study, participants performed a card-sorting task on the items of the questionnaires that are most frequently used to assess specific and general pain-relevant anxiety constructs. All items were presented separately on small cards that had to be sorted into piles according to perceived similarity in content. Prior studies have used the similarity card-sorting task to detect the underlying dimensional structure and the components of pain behavior as described by a broad range of pain descriptive words (Clark, Ferrer Brechner, Janal, Carroll, \& Yang, 1989; Clark, Janal, Hoben, \& Carroll, 2001; Turk, Wack, \& Kerns, 1985; Verkes, Van der Kloot, \& Van der Meij, 1989; Vlaeyen, van Eek, Groenman, \& Schuerman, 1987) or to detect the organizational structure of implicit personality theory or human goals (Chulef, Read, \& Walsh, 2001; Rosenberg \& Gara, 1983). By using multidimensional scaling and cluster analyses, the present study seeks to find empirical support for the proposed hierarchical structure of pain-related anxiety constructs. It considers the formation of clusters along the lines of the hierarchical nodes and proposes a content-specificity dimension running from the bottom (specific) to the top (general) of the hierarchical structure. Furthermore, by examining the grouping of individual questionnaire items into meaningful clusters based on content similarity, the authors aim to shed light on the question of whether it is appropriate to consider multiple independent questionnaires to represent supposedly unique pain-relevant constructs.

\section{Method}

\section{Participants}

Participants included 294 undergraduate students enrolled in a health psychology course: 151 from Ghent University, Belgium, and 143 from Maastricht University, the Netherlands. All participants provided information on their age, gender, and the presence and duration of any pain complaints at the moment of testing. The data of 45 participants were removed from further analyses because participants provided incomplete or unreliable data sets (see Data Screening and Data Preparation section below). This means that analyses were conducted on the card-sorting outcomes of 249 participants, of whom 214 were women and whose average age was 21 years $(S D=1.80$, range $=18-29)$. Two participants in this group did not provide demographical information. Thirty-seven percent of the respondents said they experienced pain at the moment of testing. Mostly, participants referred to minor pains such as stomach pains, headaches, sore throats, or pain in wrists or ankles. Menstrual periods, colds, sprains, or recent sports injuries were indicated as the causes of these pains. Of the group experiencing pain, $21 \%$ reported that the pain complaints had been persisting over 3 months, and $20 \%$ reported that the pain interfered with the performance of daily activities. For this group, pain was mostly localized in the back, neck, shoulder, knee, or wrist. Explanations given were the aftereffects of surgery, sports accidents, or car accidents.

\section{Materials and Measures}

Card-sorting task and selection of sorting stimuli. The items of 10 questionnaires (125 items; see supplemental online material) were printed on small cards (approximately $7 \mathrm{~cm} \times 4 \mathrm{~cm}$ ), without 
answer alternatives being provided. The self-report measures were chosen so as to represent well-validated measures for the relevant hierarchical constructs (i.e., negative affectivity, trait anxiety, anxiety sensitivity, injury/illness sensitivity, fear of pain, pain catastrophizing, and physical concerns). To minimize any effects of lexical or grammatical similarities on the participants' sorting choices, some items were reformulated, and reverse-scored items were excluded. Wherever possible, questionnaires having a salient item format were replaced with other questionnaires assessing the same construct (see description of questionnaires below for details). Furthermore, when several questionnaires were available for one and the same construct, the shortest questionnaire was chosen. To control for serial order effects, we created three random sets of item sequences with the restriction that no more than three items of the same questionnaire followed each other in each sequence. Each set thus contained identical items but differed from the other sets with respect to the serial positioning of the items. The sets were randomly distributed to participants, with 92 participants receiving Set 1; 75 participants receiving Set 2; and 82 participants receiving Set 3 .

Item selection. Negative affectivity is represented by all 14 items of the Negative Emotionality subscale (NEM) of the Multidimensional Personality Questionnaire (Tellegen, 1982). High scores on the NEM indicate a nervous, apprehensive, irritable, and emotionally labile personality profile. Trait anxiety was represented by items from the Anxiety subscale of the Hospital Anxiety and Depression Scale (HADS; Spinhoven, Ormel, Sloekers, \& Kempen, 1997) and the trait form of the State Trait Anxiety Inventory (STAI-T; Spielberger, Gorsuch, Lushene, Vagg, \& Jacobs, 1983). A high score on these scales reflects a high general anxiety disposition. The Anxiety subscale of the HADS contains seven items. One HADS item was excluded because of its reversed scoring format. Only the 10 negatively stated items of the STAI-T were included.

AS and IS were represented by all items of the ASI (Peterson \& Heilbronner, 1987) and the ISI (Taylor, 1993), respectively. The ASI contains 16 statements that assert the negative consequences of experiencing anxiety and consists of three subscales, namely Physical Concerns (8 items), Cognitive Concerns (4 items), and Social Concerns (4 items; e.g., Peterson \& Heilbronner, 1987; Zinbarg, Barlow, \& Brown, 1997). Recent studies have suggested that it is especially the Physical Concerns subscale that is relevant to the context of pain (e.g., Keogh, 2004; Stewart \& Asmundson, 2006). The ISI contains 11 items, 6 of which refer to the fear of illness and 5 to the fear of injury.

Several questionnaires were included to represent the constructs that are situated at the lowest level of the hierarchical structure. Pain catastrophizing was represented by all 13 items of the PCS (Sullivan et al., 1995). Because the items of the PCS are characterized by a typical wording format (e.g., "When I am in pain ... I cannot think of anything besides my pain"), these items were slightly reworded (e.g., "I cannot think of anything besides my pain"). All 20 items of the short form of the PASS-20 (McCracken \& Dhingra, 2002) were included to represent fear of pain. This measure contains four subscales, namely Fearful Appraisal of Pain (5 items), Cognitive Anxiety (5 items), Physiological Anxiety (5 items), and Escape/Avoidance Behavior (5 items). In addition, 13 items of the Tampa Scale of Kinesiophobia (TSK; Miller, Kori, \& Todd, 1991) were incorporated to assess fear of injury and reinjury due to movement. Four items of the TSK were excluded from the present study because of their reversed scoring format. Excluding the inversely scored items, the TSK is proposed as consisting of two subscales: Somatic Focus ( 8 items) and Activity Avoidance (5 items; (Goubert et al., 2004; Roelofs, Goubert, et al., 2004). All 16 items of the Fear-Avoidance Beliefs Questionnaire (FABQ; Waddell, Newton, Henderson, Somerville, \& Main, 1993) were incorporated to represent (a) fearful beliefs about the effects of work and physical activities on pain and (b) the avoidance of activities. The FABQ contains the following two subscales: Beliefs About Work-Related Activities (11 items) and Beliefs About Physical Activities (5 items).

All items were presented in Dutch after being extracted from validated Dutch translations (obtained by a state-of-the-art translation and back-translation procedure) of the original English questionnaires, that is, the NEM (Stegen, van Diest, van de Woestijne, \& van den Bergh, 2000), the STAI (van der Ploeg, Defares, \& Spielberger, 1980), the HADS (Spinhoven et al., 1997), the ASI and ISI (Vancleef et al., 2006), the PCS (Crombez \& Vlaeyen, 1996), the TSK (Vlaeyen, Kole Snijders, Rotteveel, Ruesink, \& Heuts, 1995), the PASS-20 (Roelofs, McCracken, et al., 2004), and the FABQ (Crombez, Vlaeyen, Heuts, \& Lysens, 1999; Vendrig, Deutz, \& Vink, 1998).

Task validity checks. We incorporated, in addition to the questionnaires representing the anxiety-related hierarchical constructs, six items of the Social Desirability Scale (SDS; Marlowe \& Crowne, 1961) to serve as control items. Because of their clearly different content, these items should be sorted into one and the same pile. This provided an additional check of the participants' ability to perform the task.

Five visual analogue scales (VASs) were used to assess the participants' perceptions of specific aspects of the card-sorting task. Three VASs measured the extent to which the task was found to be tiring, boring, or interesting. One VAS evaluated the degree of legibility of the cards, and another concerned the level of concentration during task performance. All VASs applied a 100-mm horizontal line, anchored by the descriptors not at all and extremely.

\section{Procedure}

At both locations (Ghent and Maastricht), participants were tested under supervision in a lecture hall. They were asked to take alternate seats in alternate rows so as to minimize the chance of influencing each other.

Each participant received an envelope containing the demographical questionnaire, the validity check questions, a written instruction sheet, a stack of 125 cards with one item printed on each of them in 12-point Arial font, and about 25 rubber bands. Participants received verbal instructions before they were allowed to open the envelopes. They were invited to read the instruction sheet carefully before initiating the card-sorting task. Furthermore, they were instructed to fill out the demographical questionnaire and the validity checks after finishing the card-sorting task. The written instructions read as follows:

As you will see, each of these cards contains a statement or sentence. You are asked to sort the cards into piles according to their meaning. So if you think that two or more cards are similar in meaning, you 
place them in the same pile. You can create as many piles as you feel are necessary.

During the sorting phase, which took 20-80 min, the experimenters answered any remaining individual questions, but no help or information on the placement of cards in piles was given. After data collection, the students were invited to a short debriefing session explaining the objectives of the experiment.

\section{Data Screening and Data Preparation}

Twenty-seven participants who handed in incomplete data sets or who created less than three piles of cards were excluded from further analyses. We assumed a result of no more than two piles to be indicative of substandard task performance. This assumption was supported by subsequent observations that participants returning a maximum of two sorting piles rated their VAS concentration as equal to or below the 10 th percentile score $(\leq 14)$. Another group of participants excluded from further analyses consisted of those who placed less than three of the control items in one and the same pile. All in all, the card-sorting data of 249 participants were analyzed.

The mean scores on the validity checks in Table 1 indicate that the remaining group of participants rated their task as moderately tiring and boring and, to a lesser extent, as interesting. Furthermore, the self-reported level of concentration during task performance was moderate. The legibility of the individual items on the cards was assessed as good. On average, the card-sorting task yielded eight piles $(S D=4$; range $=3-22$ ).

A $125 \times 125$ frequency matrix was created on the basis of the sorting data, with each cell representing the number of times that two cards were placed together. The value of each cell therefore ranges from 0 to 249 , and the value 1 is to be found on the diagonal of the matrix. In this similarity matrix, higher cell numbers indicate a higher degree of perceived similarity for the items that are connected by that cell.

\section{Statistical Analyses}

Multidimensional scaling (MDS; Proxscal, SPSS 11.0) was used to identify underlying dimensions of the obtained data. MDS represents the items in a geometrical configuration of points in such a manner that highly similar items are placed close to each other, and items with low similarity are placed at a greater distance from each other. The stress value, which is the principal measure of model fit, was used to decide on the most appropriate dimensional solution (Kruskal \& Wish, 1978).

Additive tree analysis (ADDTREE/P; Corter, 1982) was conducted to explore the grouping of individual card-sorting items

Table 1

Descriptive Statistics on the Validity Checks $(N=249)$

\begin{tabular}{lccr}
\hline Visual analogue scale & $M$ & $S D$ & Range \\
\hline Tiring & 48.43 & 28.74 & $0-100$ \\
Concentration & 54.29 & 20.23 & $2-100$ \\
Interesting & 33.83 & 22.72 & $0-100$ \\
Legible & 78.93 & 19.40 & $14-100$ \\
Boring & 56.71 & 26.88 & $0-100$ \\
\hline
\end{tabular}

into interpretable clusters. Tree modeling can be applied to proximity data (either similarity or dissimilarity data) on conceptual object pairs. Additive tree models have been proposed as being less restrictive than are ultrametric tree models (e.g., a hierarchical tree resulting from hierarchical cluster analyses) because, unlike ultrametric tree models, they do not impose constraints on the data on the basis of the ultrametric inequality principle (Corter, 1996; Sattah \& Tversky, 1977). According to this principle, intracluster distances are always smaller than are intercluster distances, and all intercluster distances are equal to each other in a given tree. As such, all external nodes in the ultrametric tree are equally distant from the root of the tree. In an additive tree, however, intercluster distances are allowed to exceed intracluster distances, and the distances between an object outside a cluster and the objects inside it are not necessarily equal. That is why additive trees are proposed as being less restrictive and more flexible than are ultrametric models (e.g., hierarchical cluster trees), as well as more suitable to represent the relations between observed items or objects in a similarity matrix (Corter, 1996; Sattah \& Tversky, 1977).

ADDTREE/P is a highly flexible, easily interpretable program that makes use of an efficient and robust combinatorial algorithm to fit tree structures to a data set (Corter, 1982, 1996). This algorithm examines and compares all possible quadruples (combinations of four elements) of objects to find an optimal set of objects to be combined at each step, on the basis of the neighbors relation (see Corter, 1996, for mathematical details). When pairs of objects are joined at one stage, they are considered a single object in all subsequent stages. The tree construction procedure results in a robust measure of closeness between each pair of objects. The tree construction is independent of the model distances (arc lengths) and employs a least-square criterion to estimate the parameters of the tree. In the graphical tree representation, the horizontal distance from an object in the tree to the root of the tree reflects the degree of similarity of this object to all other objects, compared with the other objects that join that particular object in the same subtree. Moreover, the distance from each object to the root of the tree may be interpreted as indicative of the typicality of this object for the whole set of objects. The arcs (connecting lines) between an object and its node can be interpreted as the weight of this object in the cluster, or as the distinctiveness of a cluster (Corter, 1996).

Thirty-seven percent $(n=92)$ of the participants reported experiencing pain at the moment of testing, and $8 \%(n=20)$ of the total sample reported having experienced pain for more than 3 months. It can be argued that these participants sorted the data in a different manner from that of the participants who were not experiencing pain. We initially checked this possibility by comparing the number of piles created by these two categories. The number of piles created by the participants without pain (mean number $=8$, range $=3-22$ ) did not differ from that of the participants reporting pain (mean number $=8$; range $=3-21$ ) or from that of the participants reporting they had had pain for more than 3 months (mean number $=8$; range $=3-22$ ). Furthermore, we conducted sensitivity analyses on two data sets: one in which the card-sorting outcomes of the 20 participants reporting having had pain for over 3 months were removed and another in which the card-sorting outcomes of 92 participants reporting pain were removed. The results of these analyses did not deviate from the tree solution and MDS solution that were obtained in the original data 
set of 249 participants. To preserve adequate statistical power, we report the analyses on the data of 249 participants in this article.

\section{Results}

\section{Multidimensional Scaling}

The MDS solution. The MDS analyses produced solutions in one to six dimensions. The scree plot (see Figure 2A) showed a "stress elbow" at two dimensions, with an observed stress value of .021, accounting for $98 \%$ of the variance in the obtained data set. Figure 2B situates each item within the two-dimensional representation of the MDS solution, as determined by the coordinates in each dimension. However, careful inspection of Figure 2B suggests that a horseshoe effect might characterize our data. The horseshoe effect is a frequently observed artifact in MDS data analyses (Davison \& Hearn,

A

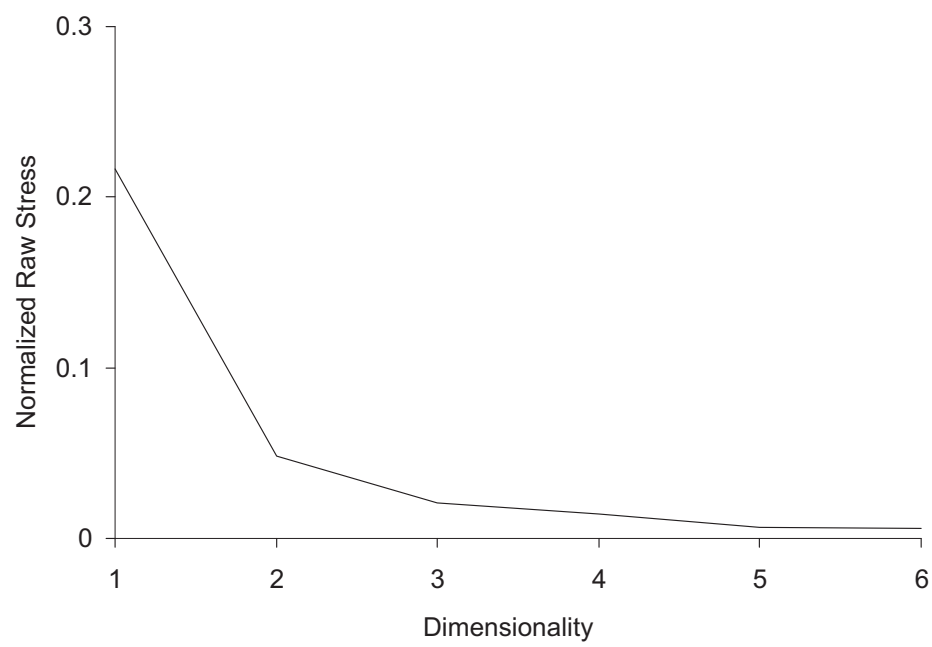

B

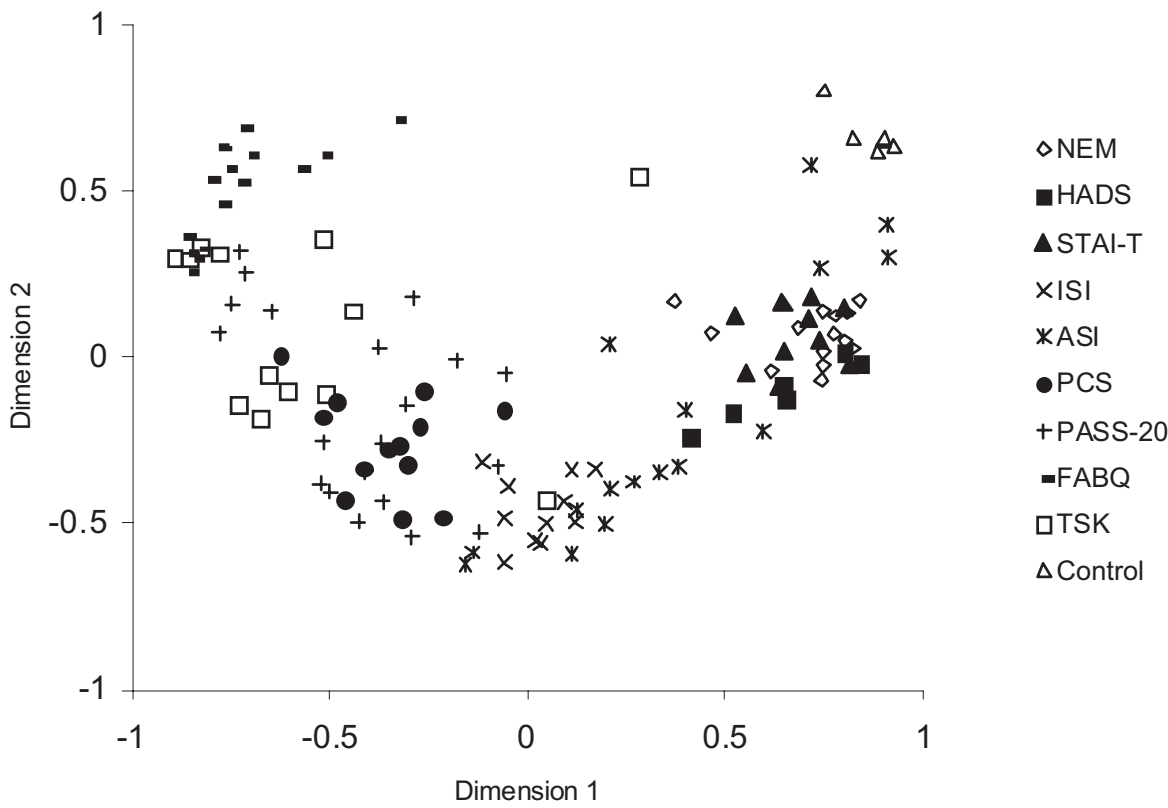

Figure 2. A: A scree plot of the multidimensional scaling solution. B: A two-dimensional scaling solution. NEM = Negative Emotionality subscale of the Multidimensional Personality Questionnaire; HADS = Hospital Anxiety and Depression Scale; STAI-T = trait form of the State Trait Anxiety Inventory; ISI = injury/illness sensitivity index; ASI $=$ anxiety sensitivity index; PCS $=$ Pain Catastrophizing Scale; PASS-20 $=$ short form of the Pain Anxiety Symptoms Scale; FABQ = Fear-Avoidance Beliefs Questionnaire; TSK = Tampa Scale of Kinesiophobia. 
1989; Diaconis, Goel, \& Holmes, 2008) and visually presents items in a two-dimensional solution when a one-dimensional solution explains the data more accurately. The stress value of the one-dimensional solution and the scree plot indicates that a one-dimensional solution fits the present data better. For the one-dimensional solution, the observed stress score is .048, accounting for $96 \%$ of the observed data. The second dimension does not add any significant change to the explanatory power of the data. Moreover, considering the interpretability of resulting dimensions as an additional decision criterion, which is of considerable importance in MDS (Kruskal \& Wish, 1978), a one-dimensional solution was decided on in the present data set.

Labeling. Labels were assigned to the obtained dimension by examining the items on both ends of the scale. Some examples of items on the positive end of this dimension are "I feel restless as if I have to be on the move" (HADS), "It is important to me to stay in control of my emotions" (ASI), and "My feelings are rather easily hurt" (NEM). On the negative end, the following items were situated: "Pain lets me know when to stop exercising so that I don't injure myself" (TSK), "My pain was caused by physical activity" (FABQ), "My work aggravated my pain" (FABQ), and "As soon as pain comes on I take medication to reduce it" (PASS-20). Items are thus represented on a sliding scale from positive to negative. On the positive end, they refer to negative emotions, feelings, and anxiety in general, and the farther we move down the scale, the more specific the content and object of the negative feelings, anxiety, and worrying become. Consequently, this dimension was labeled general negative concerns-pain-specific negative concerns.

\section{ADDTREE/P Solution}

The additive tree solution is presented in Figure 3. The mathematical solution of this tree resulted in a stress score of $.07\left(R^{2}=\right.$ .87). The additive tree reveals four main groups of items, in which meaningful subgroups can be detected (see Table 2).

Interpreting main clusters and subclusters in the additive tree. The first main cluster contains items that refer to negative moods, negative emotions, feelings of distress, worries, nervousness, and anxiety, without entailing any specific referral to pain, physical health, or bodily symptoms. We therefore labeled this first main cluster general negative emotions and anxiety. This main cluster contains two clearly distinguishable subclusters. The first subcluster reflects negative cognitions about how people's behavior or health problems are perceived and evaluated by others. The label negative view of others' perceptions therefore seems to summarize this subcluster appropriately. The second subcluster reflects negative emotions, distress, worrying, nervousness, and anxiety in general and can thus be labeled negative affect. One item of the HADS ("I get a sort of frightened feeling as if something awful is about to happen") is only loosely linked to the second subcluster. This item describes the negative feelings that accompany premonitions of future events. This sense of forewarning is not implied in the other items in this second subcluster, and this particular item might therefore be said to refer to generalized anxiety.

The second main cluster forms a tight and distinct combination of two items of the mental concerns subscale of the ASI. The close relation between these two items can be understood from their

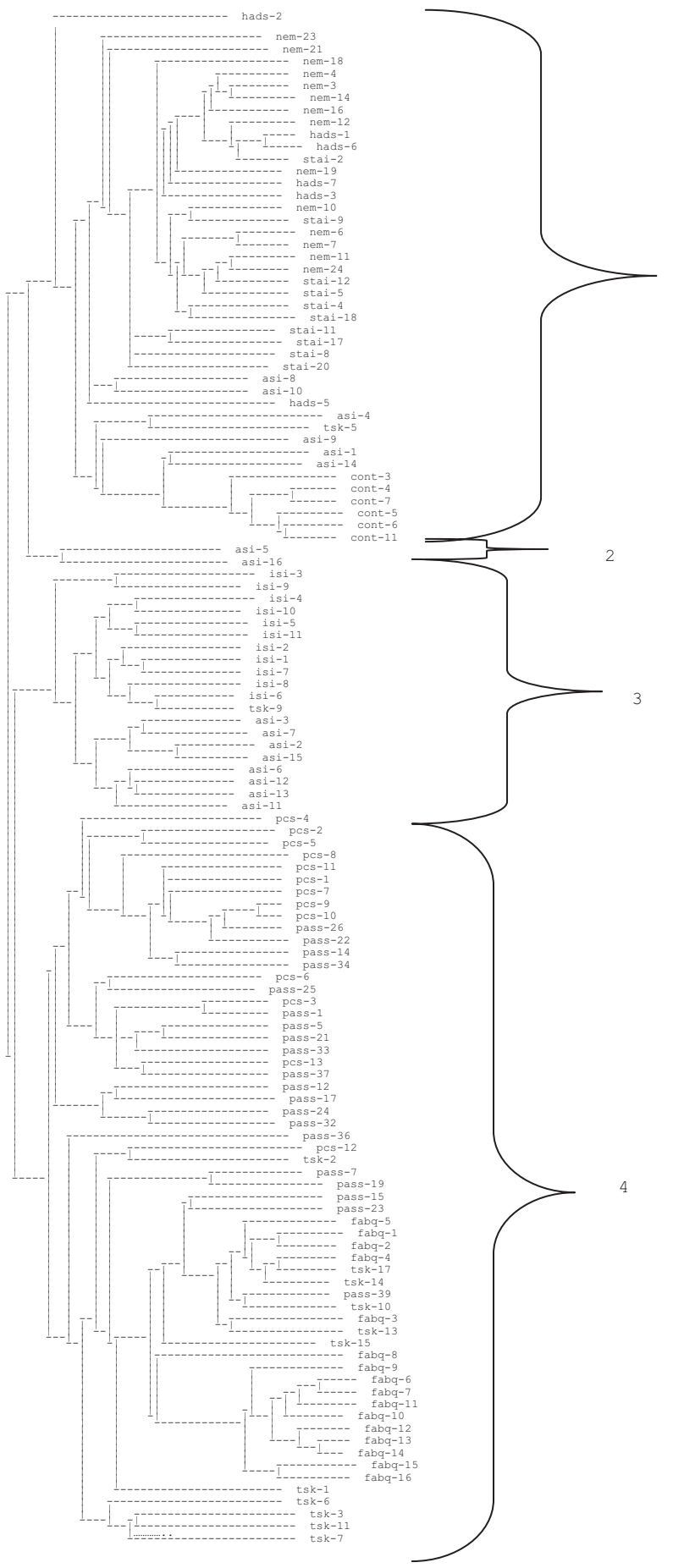

Figure 3. Additive tree solution. hads $=$ Hospital Anxiety and Depression Scale; nem = Negative Emotionality subscale of the Multidimensional Personality Questionnaire; stai $=$ State Trait Anxiety Inventory; asi $=$ anxiety sensitivity index; tsk $=$ Tampa Scale of Kinesiophobia; cont $=$ control; isi $=$ injury/illness sensitivity index; $p c s=$ Pain Catastrophizing Scale; pass = Pain Anxiety Symptoms Scale (the PASS-20, a short form of the PASS, was used, but item numbers are according to the original PASS); fabq = Fear-Avoidance Beliefs Questionnaire. 
Table 2

Meaningful (Sub)Clusters in the Additive Tree Solution

\begin{tabular}{|c|c|c|c|}
\hline Main cluster & Subclusters & Items & Item description \\
\hline \multirow{3}{*}{$\begin{array}{l}\text { 1. Negative } \\
\text { emotions and } \\
\text { anxiety }\end{array}$} & $\begin{array}{l}\text { 1.1 Negative view on } \\
\text { others' perceptions }\end{array}$ & $\begin{array}{l}\text { Control items; } \\
\text { ASI } 1,4,9,14 \\
\text { TSK } 5\end{array}$ & $\begin{array}{l}\text { Negative cognitions concerning the way } \\
\text { in which others perceive and evaluate a } \\
\text { person's physical health complaints }\end{array}$ \\
\hline & 1.2 Negative affect & $\begin{array}{l}\text { NEM; HADS; STAI; } \\
\text { ASI } 8,10\end{array}$ & $\begin{array}{l}\text { Negative mood, negative emotions, } \\
\text { distress, worrying, nervousness, and } \\
\text { anxiety with no specific referral to pain, } \\
\text { physical health, or bodily symptoms }\end{array}$ \\
\hline & 1.3 Generalized anxiety & HADS 2 & $\begin{array}{l}\text { "I get a sort of frightened feeling as if } \\
\text { something awful is about to happen." }\end{array}$ \\
\hline \multirow{2}{*}{$\begin{array}{l}\text { 2. Cognitive } \\
\text { performance } \\
\text { concerns }\end{array}$} & & ASI 5,16 & Attention, concentration \\
\hline & 3.1 Physical concerns & $\begin{array}{l}\text { ASI } 2,3,6,7,11 \\
12,13,15\end{array}$ & $\begin{array}{l}\text { Fear of anxiety related bodily sensations } \\
\text { (e.g. sweating, nausea, heart palpitations) }\end{array}$ \\
\hline \multirow{2}{*}{$\begin{array}{l}\text { 3. Physical } \\
\text { health concerns }\end{array}$} & Fear of & $\begin{array}{l}\text { ISI } 1,2,4,5,6,7,8, \\
10,11 ; \text { TSK } 9\end{array}$ & $\begin{array}{l}\text { Worrying and catastrophizing thoughts } \\
\text { about potential physical illness or injury }\end{array}$ \\
\hline & 3.3 & ISI 3,9 & $\begin{array}{l}\text { "It would be awful to have a serious } \\
\text { illness"; "It would be awful to be injured } \\
\text { in any way." }\end{array}$ \\
\hline \multirow{3}{*}{$\begin{array}{l}\text { 4. Pain-specific } \\
\text { concerns }\end{array}$} & 4.1 Catastrophizing & $\begin{array}{l}\text { PCS } 1,2,3,4,5,6 \\
7,8,9,10,11,13 ; \\
\text { PASS } 1,5,14,21 \\
22,25,26,33,34,37\end{array}$ & $\begin{array}{l}\text { Catastrophic cognitions concerning the } \\
\text { negative impact of pain on physical and } \\
\text { mental functioning; the uncontrollable } \\
\text { nature of pain; feelings of helplessness }\end{array}$ \\
\hline & $\begin{array}{l}4.2 \text { Physiological } \\
\text { anxiety }\end{array}$ & $\operatorname{PASS} 12,17,24,32$ & Physiological anxiety in response to pain \\
\hline & 4.3 Escape/avoidance & $\begin{array}{l}\text { PCS 12; PASS } 7,15 \\
19,23,36,39 ; \\
\text { FABQ; TSK } 1,2,3 \\
6,7,10,11,13,14 \\
15,17\end{array}$ & $\begin{array}{l}\text { Impact that activity and work will have on } \\
\text { the deterioration and persistence of pain } \\
\text { problems }\end{array}$ \\
\hline
\end{tabular}

Note. ASI = anxiety sensitivity index; TSK = Tampa Scale of Kinesiophobia; NEM = Negative

Emotionality subscale of the Multidimensional Personality Questionnaire; HADS = Hospital Anxiety and Depression Scale; STAI-T = trait form of the State Trait Anxiety Inventory; ISI = injury/illness sensitivity index; PCS = Pain Catastrophizing Scale; PASS-20 = short form of the Pain Anxiety Symptoms Scale (item numbers are according to the original PASS); FABQ $=$ Fear-Avoidance Beliefs Questionnaire.

specific content, which reflects concerns and negative beliefs that people may have when they are unable to keep focused. Unlike any other items included in the data set, items in this cluster refer to attentional and concentration problems, so the cluster is labeled cognitive performance concerns.

The third main cluster combines items that reflect anxiety, worrying, and catastrophic cognitions concerning health, injury, illness, and the meaning of internal bodily sensations. Since items in this main cluster are characterized by a specific reference to existing or potential physical health problems, this cluster is labeled physical health concerns. Two demarcated subclusters can be derived from this main cluster. The first subcluster, labeled physical concerns, contains ASI physical concerns items only. The second subcluster, which contains all but two items of the ISI and one TSK item, is labeled fear of injury and illness. The third main cluster seems to contain another subcluster, one that combines two ISI items that reflect how "awful" it would be to get injured or have a serious physical injury. Although these two items appear to form a distinct cluster because of their markedly negative formulation (i.e., "awful"), we decided that, given their content, they should rather be interpreted as belonging to the fear of injury and illness subcluster.

The fourth main cluster covers catastrophic cognitions and negative beliefs regarding (a) the impact of pain on physical and mental functioning and (b) the uncontrollable nature of pain, and therefore the cluster is labeled pain-specific concerns. This main cluster comprises three meaningful and interpretable subclusters of items. The first subcluster reflects catastrophic cognitions and cognitive anxiety regarding the impact of pain on physical and mental functioning. This cluster is labeled catastrophizing. The second subcluster contains all items of the physiological anxiety subscale of the PASS-20 and is labeled physiological anxiety. The third subcluster - containing all FABQ items, all items of the TSK (except those that appeared in the first and third main clusters), and 
all items from the PASS-20 escape-avoidance behavior subscale-is labeled escape/avoidance.

Interpreting relative distances from items to the root of the tree. The additive tree that results from the ADDTREE/P program also provides information on the extent to which items form a typical representation of the entire set of items (Corter, 1996). As such, the entire data set (i.e., all items) is assumed to reflect the broad concept of negative emotions relevant to pain, since all items of the card-sorting task were derived from self-report instruments assessing pain-relevant negative emotionality constructs. The degree to which an item represents this broad concept is given by its distance to the root of the tree. Figure 3 shows that items of the ASI, the ISI, and the Physical Sensations subscale of the PASS-20 are closest to the root of the tree, which suggests that of all items in the present data set these are the most representative of negative emotions relevant to pain. By contrast, the control items of the SDS and the FABQ sets are farthest from the root of the tree, which indicates that these items are less representative of pain-relevant negative emotions.

\section{Discussion}

The present study applied empirical methods to examine the proposed hierarchical organization of pain-related negative emotional constructs. It considered the dimensional structure and the cluster formation of the most elementary representatives of the constructs in the model (i.e., the individual items of the scales that serve as their operationalization; Keogh \& Asmundson, 2004; Lilienfeld et al., 1993).

The additive tree analysis revealed four main clusters within the present data set: (1) negative emotions and anxiety, (2) cognitive performance concerns, (3) physical health concerns, and (4) painspecific concerns. In terms of the hierarchical structure, Cluster 1 can be conceived as representing the upper two general negative construct levels, Cluster 2 and Cluster 3 represent the fundamental fear level, and Cluster 4 reflects the pain-specific lowest level of the model. The analysis also revealed the existence of meaningful groups and subgroups within each main group that corresponded largely to the individual components of the proposed hierarchical structure (i.e., negative affect, physical concerns, fear of injury and illness, catastrophizing, escape/avoidance and harm). Besides supporting a hierarchical organization of distinguishable pain-relevant negative constructs, the present study provides empirical evidence for a general-specific dimensionality underlying the constructs in the hierarchical model (Lilienfeld et al., 1993; Watson \& Clark, 1992).

The additive tree solution produced some interesting outcomes on the self-report measures that serve as the operationalization of the constructs in the hierarchical model. First, items of general measures (i.e., negative affectivity and dispositional anxiety) were found to be scattered over three subclusters of the first main cluster, while items of specific measures (i.e., anxiety sensitivity, injury/illness sensitivity, and fear of pain) showed less dispersion across subclusters. This finding offers additional support for the general-specific dimensionality as observed in the MDS solution. Items from the general measures are not bound to form tight clusters because they share the same focus, namely negative affect. The spreading of the general measure items over different subclusters furthermore corroborates the suggestion that negative af- fectivity and dispositional anxiety share similar characteristics and reflect the same psychological construct (Barlow, 2000; Zinbarg \& Barlow, 1996). On the other hand, items of specific measures form tighter clusters that represent the specific focus or object characteristic of each specific construct (e.g., injury, illness, disability, bodily sensations). This finding reemphasizes the importance of considering the object of fear or anxiety when working with various emotional constructs in pain research (Morley \& Eccleston, 2004).

Second, the present ADDTREE solution shows that for most self-report measures (i.e., the NEM, the STAI-T, the ISI, the HADS, the PCS, the FABQ, and the PASS-20), items that belong to the same scale are grouped together in the same main cluster. This not only indicates that the items of these scales are perceived as highly similar to each other, but also points to item homogeneity and coherence of these individual measures.

On a subcluster level, meaningful subclusters are rarely found to contain items of one questionnaire only; rather, they are formed by a combination of items from different scales. This outcome offers further support for the constructional strength of the self-report instruments. It is generally acknowledged that, for a questionnaire to cover all components of the construct it aims to tap, the contents of its items should be characterized by a balanced degree of variability and overlap (e.g., Kline, 2000).

On the other hand, in view of the interscale clustering of items, we should be wary of relying on any singular self-report measure to model a latent construct from the proposed hierarchical structure. As the present data show, we should not assume a one-to-one relation between a specific questionnaire and the construct it intends to reflect.

Third, it is remarkable that the ASI and the PASS-20 items cluster on the level of their respective subscales. The items of the ASI Physical Concerns subscale cluster in a physical concerns subgroup and merge with all ISI items in the physical health concerns main cluster. The other two subscales of the ASI are found to cluster in the negative emotions and anxiety main cluster. The cluster behavior of ASI items corroborates the idea that the Physical Concerns subscale of the ASI is of particular importance when examining the construct of AS in the domain of pain (Asmundson, Wright, Norton, \& Veloso, 2001; Drahovzal, Stewart, \& Sullivan, 2006; Keogh, 2004). Furthermore, it might be speculated that formerly observed associations between AS and IS predominantly originate from associations between the ISI and the ASI Physical Concerns subscale (Carleton, Asmundson, \& Taylor, 2005; Vancleef \& Peters, 2008; Vancleef, Peters, Gilissen, \& de Jong, 2007; Vancleef et al., 2006). Additionally, the distribution of ASI subscales across main clusters of varying specificity levels makes it difficult to consider ASI total scores when examining AS in the context of pain. After all, varying levels of specificity, and hence varying degrees of focus on anxiety or fear, are assumed to contribute to divergent responses to pain (e.g., Hadjistavropoulos et al., 2004; McCracken et al., 1996). The ASI total scores do not reveal the unique predictive potential of AS subfactors for different aspects of the pain problem. This failure might lead to erroneous conclusions on the role of AS in pain. It is therefore advisable to use the ASI subscales when examining the contribution of AS to pain.

Unlike the ASI items, the PASS-20 items cluster within one main group (i.e., pain-specific concerns), with all items being 
characterized by a similar level of specificity. However, the ADDTREE solution shows that two of the four PASS-20 subscales are grouped with the PCS items into the catastrophizing subcluster. The Physiological Anxiety subscale forms a demarcated subcluster, and the Escape/Avoidance subscale merges with FABQ and TSK items in the escape/avoidance subcluster. The clustering of PASS-20 items at the subscale level stresses the importance and relevance of using the subscales of the PASS-20 to predict responses to pain (Coons, Hadjistavropoulos, \& Asmundson, 2004; McCracken et al., 1996).

The fact that the ASI and the PASS-20 items are split up into subscales suggests that the subscale scores rather than the total scores of these questionnaires should be used in pain research. By contrast, the FABQ, the ISI, the TSK, and the PCS are not found to cluster on a subscale level, so adopting the subscales of these particular measures in pain research does not seem to be meaningful. This outcome contrasts with results of psychometric studies that have advocated the existence of meaningful subscales in the ISI (Carleton et al., 2005), the TSK (Goubert et al., 2004; Roelofs et al., 2007; Woby, Roach, Urmston, \& Watson, 2005), the PCS (Sullivan et al., 1995), and the FABQ (Waddell et al., 1993). Conversely, a number of studies have demonstrated the validity of working with total scores of the PCS, the TSK, and the ISI when examining their contribution to pain (Carleton et al., 2005; Goubert et al., 2004; Osman et al., 2000; Ostelo, SwinkelsMeewisse, Knol, Vlaeyen, \& de Vet, 2007; Severeijns, van den Hout, Vlaeyen, \& Picavet, 2002; Sullivan et al., 1995; Vancleef et al., 2006). Future studies will have to demonstrate whether it is meaningful to consider subscales of these measures in pain research. It is important to note that the present study is the first to examine respondents' understanding of the semantic meaning of questionnaire items that represent pain-relevant negative emotions. In other words, these findings definitely require replication before any firm conclusion can be made on the appropriateness of adopting subscale or total scores for these measures.

Fourth, the additive tree provides information on the extent to which each individual item represents the general concept of "pain-relevant emotional constructs." Being closest to the root of the tree, the items of the ISI, the ASI's physical concerns subscale, the PASS-20's Escape/Avoidance subscale, and the TSK's Somatic Focus subscale can be interpreted as the most prototypical examples of the general concept represented by the total item set. By contrast, the control and FABQ items are most distally related to the root of the tree. The FABQ items refer to fear/avoidance beliefs about the potential harmful consequences of activity and work on pain, rather than to negative affective states because of the pain (anxiety, worrying, catastrophizing; Waddell et al., 1993). These fear/avoidance beliefs are therefore less suitable to represent pain-relevant negative emotions. In a similar vein, items of the PASS-20 Escape/Avoidance subscale and the TSK ActivityAvoidance subscale are found to show distal relations with the concept of pain-relevant negative emotions.

Several limitations have to be taken into account when interpreting the present findings. Obviously, a considerable degree of subjectivity in interpreting the resulting dimensions and clusters is inherent in the exploratory methods used in this study. Also, our sample of undergraduate students may not have perceived the content of the items in a way that is representative of, for example, pain patients or persons belonging to other age cohorts. But then, the present study aimed to examine if respondents to different pain-research questionnaires indeed perceived them as dissimilar with respect to their item content. Importantly, quite a few of the studies that used these instruments were in fact conducted in healthy student samples like ours, and there is no reason to assume that students' interpretation of the semantic meaning of the items used in this study would be different from other people's. Students may use a more superficial sorting strategy compared with that of older individuals or pain patients because they have less experience with pain, but this is not borne out by our data. The participants in our experiment created a relatively large number of piles, and the cluster solution was highly interpretable and corresponded well to the different pain-related anxiety constructs proposed. Nevertheless, replication of the present findings in other samples is strongly recommended.

Future studies should address the external validity by including items from self-report scales that intend to tap the same latent constructs as the self-report measures that were incorporated in the present study, for example, the Depression Anxiety Stress Scale (Lovibond \& Lovibond, 1995), the Survey of Pain Attitudes (Jensen, Turner, Romano, \& Lawler, 1994), and the Fear of Pain Questionnaire (McNeil \& Rainwater, 1998). The choice of items included in our study (the input) naturally determined the resulting organizational structure in clusters and dimensions (the output). This means that the present findings cannot be generalized to the wider area of negative emotional disorders. Other cluster solutions may result when self-report measures for other negative emotional constructs are incorporated as well, for example, the Fear of Negative Evaluation Scale (Leary, 1983), the Beck Depression Inventory (Beck, Steer, \& Garbin, 1988), and the Social Phobia and Anxiety Inventory (Turner, Beidel, Dancu, \& Stanley, 1989).

In conclusion, this study demonstrates that naïve participants (i.e., those who do not possess prior knowledge of the organizational structure of the 125 items in the card set) are well able to categorize items of different self-report measures into the theoretical constructs that they represent. They were found capable of perceiving items of various questionnaires as different from each other and of recognizing the differences in specificity level that characterize different questionnaires. Future research can take advantage of this finding because it demonstrates the appropriateness of holding on to different questionnaires to assess different pain-relevant emotional constructs. This is especially true for the pain-specific measures. However, caution is warranted when separate questionnaires (e.g., NEM, HADS, STAI-T) are used to assess the general measures, since items of these measures are found to be more dispersed within one main cluster. This study further demonstrates that for some pain research questionnaires it is more suitable to use the subscale scores than the total scores. Most importantly, to our knowledge this study is the first to provide empirical support for the dimensional and componential structure of a hierarchical organization of pain-relevant negative emotional constructs. Because findings could be interpreted along the lines of the proposed hierarchical structure, it is recommendable to conduct further research on the conceptualization of painrelevant emotional constructs. Such research should include formal statistical testing of the hierarchical model to clarify the merits of working with hierarchical constructs in explaining maladaptive behavioral, cognitive, and affective responses to pain and disability. 


\section{References}

Asmundson, G. J. G., Wright, K. D., Norton, P. J., \& Veloso, F. (2001). Anxiety sensitivity and other emotionality constructs in predicting headache medication use in patients with recurring headaches: Implications for abuse and dependency. Addictive Behaviors, 26, 827-840.

Barlow, D. H. (2000). Unraveling the mysteries of anxiety and its disorders from the perspective of emotion theory. American Psychologist, 55, $1247-1263$.

Beck, A. T., Steer, R. A., \& Garbin, M. G. (1988). Psychometric properties of the Beck Depression Inventory: Twenty-five years of evaluation. Clinical Psychology Review, 8, 77-100.

Carleton, N. R., Asmundson, G. J. G., \& Taylor, S. (2005). Fear of physical harm: Factor structure and psychometric properties of the injury/illness sensitivity index. Journal of Psychopathology and Behavioral Assessment, 27, 235-241.

Chulef, A. S., Read, S. J., \& Walsh, D. A. (2001). A hierarchical taxonomy of human goals. Motivation and Emotion, 25, 191-232.

Clark, W. C., Ferrer Brechner, T., Janal, M. N., Carroll, J. D., \& Yang, J. C. (1989). The dimensions of pain: A multidimensional scaling comparison of cancer patients and healthy volunteers. Pain, 37, 23-32.

Clark, W. C., Janal, M. N., Hoben, E. K., \& Carroll, J. D. (2001). How separate are the sensory, emotional, and motivational dimensions of pain? A multidimensional scaling analysis. Somatosensory and Motor Research, 18, 31-39.

Coons, M. J., Hadjistavropoulos, H. D., \& Asmundson, G. J. G. (2004). Factor structure and psychometric properties of the Pain Anxiety Symptoms Scale-20 in a community physiotherapy clinic sample. European Journal of Pain, 8, 511-516.

Corter, J. E. (1982). ADDTREE/P: A PASCAL program for fitting additive trees based on Sattah and Tversky's ADDTREE algorithm. Behavior Research Methods, Instruments, \& Computers, 14, 353-354.

Corter, J. (1996). Tree models of similarity and association. Thousand Oaks, CA: Sage.

Crombez, G., Eccleston, C., Baeyens, F., Van Houdenhove, B., \& Van Den Broeck, A. (1999). Attention to chronic pain is dependent upon painrelated fear. Journal of Psychosomatic Research, 47, 403-410.

Crombez, G., \& Vlaeyen, J. W. S. (1996). The Pain Catastrophizing Scale. Unpublished translation from Dutch/Flemish.

Crombez, G., Vlaeyen, J. W. S., Heuts, P. H. T. G., \& Lysens, R. (1999). Pain-related fear is more disabling than pain itself: Evidence on the role of pain-related fear in chronic back pain disability. Pain, 80, 329-339.

Davison, M. L., \& Hearn, M. (1989). Two-dimensional configurations of unidimensional stimulus sets in nonmetric multidimensional scaling. Applied Psychological Measurement, 13, 329-334.

Diaconis, P., Goel, S., \& Holmes, S. (2008). Horseshoes in multidimensional scaling and kernel methods. Annals of Applied Statistics, 2, 777-807.

Drahovzal, D. N., Stewart, S. H., \& Sullivan, M. J. L. (2006). Tendency to catastrophize somatic sensations: Pain catastrophizing and anxiety sensitivity in predicting headache. Cognitive Behaviour Therapy, 35, 226235

Goubert, L., Crombez, G., Van Damme, S., Vlaeyen, J. W. S., Bijttebier, P., \& Roelofs, J. (2004). Confirmatory factor analysis of the Tampa Scale for Kinesiophobia: Invariant two-factor model across low back pain patients and fibromyalgia patients. Clinical Journal of Pain, 20, 103-110.

Hadjistavropoulos, H. D., Asmundson, G. J. G., \& Kowalyk, K. M. (2004). Measures of anxiety: Is there a difference in their ability to predict functioning at three-month follow-up among pain patients? European Journal of Pain, 8, 1-11.

Jensen, M. P, Turner, J. A., Romano, J. M., \& Lawler, B. K. (1994). Relationship of pain specific beliefs to chronic pain adjustment. Pain, 57, 301-309.

Keogh, E. (2004). Investigating invariance in the factorial structure of the anxiety sensitivity index across adult men and women. Journal of Personality Assessment, 83, 153-160.

Keogh, E., \& Asmundson, G. J. G. (2004). Negative affectivity, catastrophizing, and anxiety sensitivity. In G. J. G. Asmundson, J. W. S. Vlaeyen, \& G. Crombez (Eds.), Understanding and treating fear of pain (pp. 91-115). New York: Oxford University Press.

Kline, P. (2000). The handbook of psychological testing (2nd ed.). London: Routledge.

Kruskal, J. B., \& Wish, M. (1978). Multidimensional scaling. Beverly Hills, CA: Sage.

Leary, M. R. (1983). A brief version of the Fear of Negative Evaluation Scale. Personality and Social Psychology Bulletin, 9, 371-375.

Lilienfeld, S. O. (1996). Anxiety sensitivity is not distinct from trait anxiety. In R. M. Rapee (Ed.), Current controversies in anxiety disorders (pp. 228-253). New York: Guilford Press.

Lilienfeld, S. O., Turner, S. M., \& Jacob, R. G. (1993). Anxiety sensitivity: An examination of theoretical and methodological issues. Advances in Behaviour Research and Therapy, 15, 147-183.

Lilienfeld, S. O., Turner, S. M., \& Jacob, R. G. (1998). Déjà vu all over again: Critical misunderstandings concerning anxiety sensitivity and constructive suggestions for future research. Journal of Anxiety Disorders, $12,71-82$.

Lovibond, S. H., \& Lovibond, P. F. (1995). Manual for the Depression Anxiety Stress Scales. Sydney, New South Wales, Australia: Psychology Foundation.

Marlowe, D., \& Crowne, D. P. (1961). Social desirability and response to perceived situational demands. Journal of Counseling Psychology, 25, 109-115.

McCracken, L. M., \& Dhingra, L. (2002). A short version of the Pain Anxiety Symptoms Scale (PASS-20): Preliminary development and validity. Pain Research and Management, 7, 45-50

McCracken, L. M., Gross, R. T., Aikens, J., \& Carnrike, C. L. M., Jr. (1996). The assessment of anxiety and fear in persons with chronic pain A comparison of instruments. Behaviour Research and Therapy, 34, 927-933.

McNeil, D. W., \& Rainwater, A. J. (1998). Development of the Fear of Pain Questionnaire-III. Journal of Behavioral Medicine, 21, 389-410.

Miller, R., Kori, S. H., \& Todd, D. (1991). The Tampa Scale for Kinesiophobia. Unpublished manuscript.

Morley, S., \& Eccleston, C. (2004). The object of fear in pain. In G. J. Asmundson, J. W. Vlaeyen, \& G. Crombez (Eds.), Understanding and treating fear of pain (pp. 163-188). New York: Oxford University Press.

Norton, P. J., \& Mehta, P. D. (2007). Hierarchical model of vulnerabilities for emotional disorders. Cognitive Behaviour Therapy, 36, 240-254.

Osman, A., Barrios, F. X., Gutierrez, P. M., Kopper, B. A., Merrifield, T., \& Grittmann, L. (2000). The Pain Catastrophizing Scale: Further psychometric evaluation with adult samples. Journal of Behavioral Medicine, 23, 351-365.

Ostelo, R. W. J. G., Swinkels-Meewisse, I. J. C. M., Knol, D. L., Vlaeyen, J. W. S., \& de Vet, H. C. W. (2007). Assessing pain and pain-related fear in acute low back pain: What is the smallest detectable change? International Journal of Behavioral Medicine, 14, 242-248.

Peters, M. L., Vlaeyen, J. W. S., \& Kunnen, A. M. W. (2002). Is painrelated fear a predictor of somatosensory hypervigilance in chronic low back pain patients? Behaviour Research and Therapy, 40, 85-103.

Peterson, R. A., \& Heilbronner, R. L. (1987). The anxiety sensitivity index: Construct validity and factor analytic structure. Journal of Anxiety Disorders, 1, 117-121

Reiss, S. (1991). Expectancy model of fear, anxiety, and panic. Clinical Psychology Review, 11, 141-153.

Reiss, S., Peterson, R. A., \& Gursky, D. M. (1988). Anxiety sensitivity, injury sensitivity, and individual differences in fearfulness. Behaviour Research and Therapy, 26, 341-345.

Reiss, S., Peterson, R. A., Gursky, D. M., \& McNally, R. J. (1986). Anxiety 
sensitivity, anxiety frequency and the prediction of fearfulness. Behaviour Research and Therapy, 24, 1-8.

Roelofs, J., Goubert, L., Peters, M. L., Vlaeyen, J. W., \& Crombez, G. (2004). The Tampa Scale for Kinesiophobia: Further examination of psychometric properties in patients with chronic low back pain and fibromyalgia. European Journal of Pain, 8, 495-502.

Roelofs, J., McCracken, L. M., Peters, M. L., Crombez, G., van Breukelen, G., \& Vlaeyen, J. W. S. (2004). Psychometric evaluation of the Pain Anxiety Symptoms Scale (PASS) in chronic pain patients. Journal of Behavioral Medicine, 27, 167-183.

Roelofs, J., Sluiter, J. K., Frings-Dresen, M. H. W., Goossens, M., Thibault, P., Boersma, K., et al. (2007). Fear of movement and (re)injury in chronic musculoskeletal pain: Evidence for an invariant two-factor model of the Tampa Scale for Kinesiophobia across pain diagnoses and Dutch, Swedish, and Canadian samples. Pain, 131, 181-190.

Rosenberg, S., \& Gara, M. A. (1983). Contemporary perspectives and future directions of personality and social psychology. Journal of Personality and Social Psychology, 45, 57-73.

Sattah, S., \& Tversky, A. (1977). Additive similarity trees. Psychometrika, 42, 319-345.

Severeijns, R., van den Hout, M. A., Vlaeyen, J. W., \& Picavet, H. S. (2002). Pain catastrophizing and general health status in a large Dutch community sample. Pain, 99, 367-376.

Sexton, K. A., Norton, P. J., Walker, J. R., \& Norton, G. R. (2003). Hierarchical model of generalized and specific vulnerabilities in anxiety. Cognitive Behaviour Therapy, 32, 82-94.

Spielberger, C. D., Gorsuch, R. L., Lushene, R. E., Vagg, P. R., \& Jacobs, G. A. (1983). Manual for the State-Trait Anxiety Inventory (Form Y). Palo Alto, CA: Consulting Psychologists Press.

Spinhoven, P. H., Ormel, J., Sloekers, P. P. A., \& Kempen, G. I. J. M. (1997). A validation study of the Hospital Anxiety and Depression Scale (HADS) in different groups of Dutch subjects. Psychological Medicine, $27,363-370$.

Stegen, K., van Diest, I., van de Woestijne, K. P., \& van den Bergh, O. (2000). Negative affectivity and bodily sensations induced by $5.5 \% \mathrm{CO}_{2}$ enriched air inhalation: Is there a bias to interpret bodily sensations negatively in persons with negative affect? Psychology \& Health, 15, 513-525.

Stewart, S. H., \& Asmundson, G. J. G. (2006). Anxiety sensitivity and its impact on pain experiences and conditions: A state of the art. Cognitive Behaviour Therapy, 35, 185-188.

Sullivan, M. J. L., Bishop, S. R., \& Pivik, J. (1995). The Pain Catastrophizing Scale: Development and validation. Psychological Assessment, 7 , $524-532$.

Sullivan, M. J. L., Stanish, W., Waite, H., Sullivan, M. E., \& Tripp, D. A. (1998). Catastrophizing, pain, and disability in patients with soft-tissue injuries. Pain, 77, 253-260.

Taylor, S. (1993). The structure of fundamental fears. Journal of Behavior Therapy and Experimental Psychiatry, 24, 289-299.

Tellegen, A. (1982). Brief manual for the Differential Personality Questionnaire. Unpublished manuscript, University of Minnesota.

Turk, D. C., Wack, J. T., \& Kerns, R. D. (1985). An empirical examination of the "pain-behavior" construct. Journal of Behavioral Medicine, 8, $119-130$.

Turner, S. M., Beidel, D. C., Dancu, C. V., \& Stanley, M. A. (1989). An empirically derived inventory to measure social fears and anxiety: The
Social Phobia and Anxiety Inventory. Psychological Assessment, 1, $35-40$.

Vancleef, L. M. G., \& Peters, M. L. (2006). Pain catastrophizing, but not injury/illness sensitivity or anxiety sensitivity, enhances attentional interference by pain. Journal of Pain, 7, 23-30.

Vancleef, L. M. G., \& Peters, M. L. (2008). Examining content specificity of negative interpretation biases with the Body Sensations Interpretation Questionnaire (BSIQ). Journal of Anxiety Disorders, 22, 401-415.

Vancleef, L. M. G., Peters, M. L., Gilissen, S. M. P., \& de Jong, P. J. (2007). Understanding the role of injury/illness sensitivity and anxiety sensitivity in (automatic) pain processing: An examination using the Extrinsic Affective Simon Task. Journal of Pain, 8, 563-572.

Vancleef, L. M. G., Peters, M. L., Roelofs, J., \& Asmundson, G. J. G. (2006). Do fundamental fears differentially contribute to pain-related fear and pain catastrophizing? An evaluation of the sensitivity index. European Journal of Pain, 10, 527-536.

van der Ploeg, H. M., Defares, P. B., \& Spielberger, C. D. (1980). Handleiding bij de zelf-beoordelingsvragenlijst ZBV. Een nederlandstalige bewerking van de Spielberger State-Trait Inventory [Manual for the "zelf-beoordelingsvragenlijst ZBV": A Dutch translation of the State Trait Anxiety Inventory]. Lisse, The Netherlands: Swets \& Zeitlinger.

Vendrig, A., Deutz, P., \& Vink, I. (1998). Nederlandse vertaling en bewerking van de Fear-Avoidance Beliefs Questionnaire [Dutch translation and modification of the Fear-Avoidance Beliefs Questionnaire]. Nederlands Tijdschrift voor Pijn en Pijnbestrijding, 18, 11-14.

Verkes, R.-J., Van der Kloot, W. A., \& Van der Meij, J. (1989). The perceived structure of 176 pain descriptive words. Pain, 38, 219-229.

Vlaeyen, J. W. S., Kole Snijders, A. M. J., Rotteveel, A. M., Ruesink, R., \& Heuts, P. H. T. G. (1995). The role of fear of movement/(re)injury in pain disability. Journal of Occupational Rehabilitation, 5, 235-252.

Vlaeyen, J. W. S., \& Linton, S. J. (2000). Fear-avoidance and its consequences in chronic musculoskeletal pain: A state of the art. Pain, 85, $317-332$.

Vlaeyen, J. W. S., van Eek, H., Groenman, N. H., \& Schuerman, J. A. (1987). Dimensions and components of observed chronic pain behavior. Pain, 31, 65-75.

Waddell, G., Newton, M., Henderson, I., Somerville, D., \& Main, C. J. (1993). A Fear-Avoidance Beliefs Questionnaire (FABQ) and the role of fear-avoidance beliefs in chronic low back pain and disability. Pain, 52, $157-168$.

Watson, D., \& Clark, L. A. (1992). Affects separable and inseparable: On the hierarchical arrangement of the negative affects. Journal of Personality and Social Psychology, 62, 489-505.

Woby, S. R., Roach, N. K., Urmston, M., \& Watson, P. (2005). Psychometric properties of the TSK-11: A shortened version of the Tampa Scale for Kinesiophobia. Pain, 117, 137-144.

Zinbarg, R. E., \& Barlow, D. H. (1996). Structure of anxiety and the anxiety disorders: A hierarchical model. Journal of Abnormal Psychology, 105, 181-193.

Zinbarg, R. E., Barlow, D. H., \& Brown, T. A. (1997). Hierarchical structure and general factor saturation of the anxiety sensitivity index: Evidence and implications. Psychological Assessment, 9, 277-284.

Received December 14, 2007

Revision received April 6, 2009 Accepted April 8, 2009 